\title{
Celiac disease complicated by lymphoma
}

\section{Introduction}

Celiac disease (CD) is a common disorder affecting up to $1 \%$ of population in several developed countries. In the recent years $\mathrm{CD}$ has been increasingly recognizedin India among adults besides children. ${ }^{1,2}$ In a recent study amongst healthy blood donors from Chandigarh, the prevalence of celiac disease was $0.56 \% .{ }^{3}$ In a population based study from Delhi, the prevalence was reported to be 1 in $96 .{ }^{4} \mathrm{~A}$ number of reports on clinical presentation and complications of $\mathrm{CD}$ in children and adults have been reported from India. Enteropathy associated T cell lymphoma (EATL) is the most common malignancy associated with celiac disease. ${ }^{5}$ However EATL in celiac disease has been rarely reported from India. ${ }^{6}$ We report here a case of celiac disease complicated with EATL.

\section{Case report}

A 57-year-old male presented to us with five days history of hematochezia and colicky abdominal pain. He denied history of vomiting, fever, weight loss, night sweats or abdominal swelling. He was diagnosed with celiac disease nine months ago at another hospital when he had presented with anemia and occasional diarrhea. He had elevated IgA anti-tissue transglutaminase antibody (IgAtTG) titres and subtotal villous atrophy was evident on duodenal biopsy. There was no family history of $\mathrm{CD}$. He had been prescribed gluten-free diet but he was not compliant.

At our hospital he was found to have pallor, mild pedal edema and no abdominal lump. His hemoglobin was $8.4 \mathrm{~g} / \mathrm{dl}$, serum albumin 3.1g/L and IgAtTG $100 \mathrm{U} / \mathrm{ml}$ (normal $<8 \mathrm{U} / \mathrm{ml}$ ). A gastroduodenoscopy showed reduced fold height in the duodenum with scalloping and grooving. Duodenal histology showed partial villous atrophy. He underwent a computed tomography and angiography which showed a mass lesion (3 $\times 2 \mathrm{~cm}$ ) in the proximal jejunum with increased vascularity. $\mathrm{He}$ had persistent colicky pain and recurrent hematochezia with a drop in hemoglobin to $6.4 \mathrm{~g} / \mathrm{dl}$. He was taken up for exploratory laparotomy four days after admission when a growth was seen $15 \mathrm{~cm}$ distal to the duodeno-jejunal flexure infiltrating the posterior abdominal wall.Another small growth was seen 25 $\mathrm{cm}$ distal to the first one. Resection and anastomosis with 10

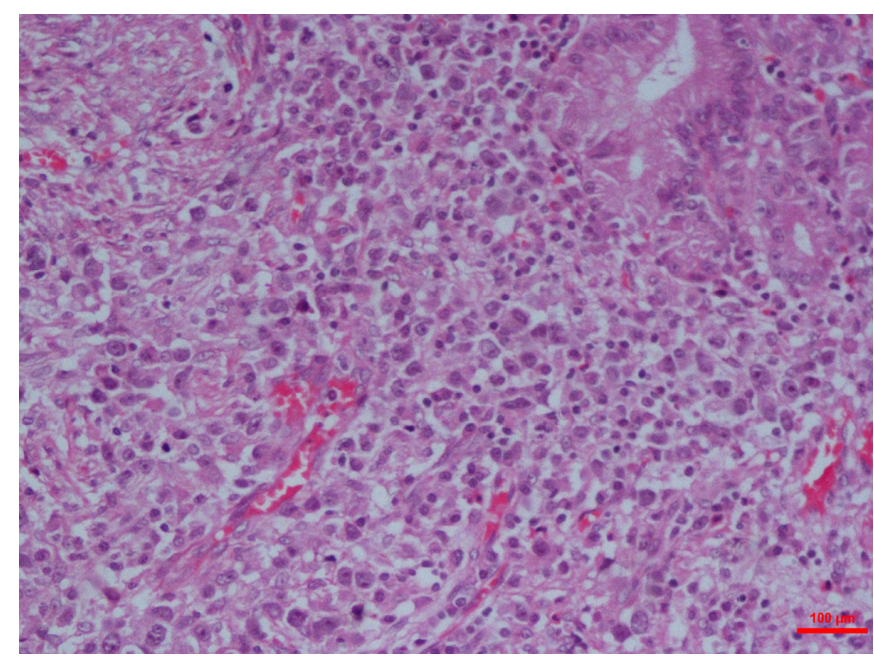

Figure 1: High power photomicrograph showing sheets of immature cells infiltrating the lamina propria intermixed with smaller and darker stained mature cells. Tumor cells are intermediate in size with eccentrically placed irregular nuclei and moderate amount of eosinophilic cytoplasm (hematoxylin and eosin, $\mathrm{x} 450$ ).

$\mathrm{cm}$ margins on both sides was carried out. Histopathology of both masses showed features of high grade tumor cells infiltrating the intestinal wall along with large areas of mucosal ulcerations (Figure 1). Tumor cells were positive for cytoplasmic $\mathrm{CD} 3$ and membranous $\mathrm{CD} 30$ but were negative for CD20. Adjoining non-tumorous mucosa showed subtotal villous atrophy with marked increase in intra-epithelial lymphocytes, muco-depletion and occasional infiltration with $\mathrm{CD} 3+\mathrm{T}$ cells. Overall features were suggestive of synchronous high grade T-cell lymphoma in the background of enteropathic mucosal changes. He developed hospital acquired infection in the post-operative period and succumbed to his illness.

\section{Discussion}

Malignancies in celiac disease are being increasingly reported. There is s 2-3 fold increased risk of developing carcinoma of the mouth, pharynx and esophagus; a30-40 fold increased risk of manifesting EALT; while the highest risk (up to 80-fold) has been noted for smallbowel adenocarcinoma. ${ }^{5}$

The association between celiac disease and lymphoma was first described by Fairly and Mackie in $1937 .^{7}$ Risk factors associated with development of EATL are prolonged duration of $\mathrm{CD}$, early onset of $\mathrm{CD}$ and poor compliance with gluten-free diet. Significant association between dietary compliance to gluten-free diet and incidence of EATL has been noted(relative risk of 77.8) and strict adherence to a gluten-free diet has been advocated to decreases the risk of lymphoma in patients with 
celiac disease ${ }^{8}$ Adherence to a gluten-free diet for more than five years reduces the risk of malignancy to that of general population. ${ }^{9}$ Weight loss, abdominal pain, change in bowel habits, vomiting, diarrhea, gastrointestinal bleed or an acute abdomen due to ulceration, obstruction or perforation are the most common presentations of EATL. ${ }^{5,10}$ The tumor can be multi-focal in distribution; hence presence of synchronous lesions should be evaluated before therapy. Our patient presented with gastrointestinal bleeding and multi-focal disease.

Although CD is being reported with increasing frequency from our country, malignancy associated with it has been sparsely reported. In a series from a cancer institute, 2 cases of EATL associated with celiac disease have been reported amongst 170 gastrointestinal lymphomas. ${ }^{6}$ In our cohort of 750 CD patients, this is the first case of EATL we have encountered. This case highlights the development of malignancy, especially EATL in patients with $C D$. With increasing prevalence of $C D$, clinicians dealing with this disease should be made aware of this complication.

JAHANGEER BASHA $^{1}$
SREEKANTH APPASANI $^{1}$
PANKAJ DIXIT $^{1}$
KIM VAIPHEI $^{2}$
KARTARSINGH $^{1}$
RAKESH KOCHHAR $^{1}$

Correspondence: Dr. Rakesh Kochhar Departments of Gastroenterology $y^{1}$ and Pathology ${ }^{2}$ Postgraduate Institute of Medical Education and Research, Chandigarh - 160012, India Email:drkochhar@hotmail.com

\section{References}

1. Poddar U, Thapa BR, Nain CK, Prasad A, Singh K. Celiac disease in India: are they true cases of celiac disease? J Pediatr Gastroenterol Nutr. 2002;35:508-12.

2. Varma S, Malhotra P, Kochhar R, Varma N, Kumari S, Jain S. Celiac disease presenting as iron-deficiency anemia in northern India. Indian J Gastroenterol. 2001;20:234-6.

3. Kochhar R, Sachdev S, Kochhar R, Aggarwal A, Sharma V, Prasad $\mathrm{KK}$, et al. Prevalence of coeliac disease in healthy blood donors: a study from north India. Dig Liver Dis. 2012;44:530-2.

4. Makharia GK, Verma AK, Amarchand R, Bhatnagar S, Das P, Goswami A, et al. Prevalence of celiac disease in the northern part of India: a community based study. J Gastroenterol Hepatol. 2011;26:894-900.

5. Meijer JW, Mulder CJ, Goerres MG, Boot H, Schweizer JJ. Coeliac disease and (extra)intestinal T-cell lymphomas: definition, diagnosis and treatment. Scand J Gastroenterol Suppl. 2004:78-84.

6. Shet T, Karpate A, Bal M, Gupta S, Gujral S, Nair R. Primary intestinal $\mathrm{T}$ cell lymphomas in Indian patients-in search of enteropathic T cell lymphoma. Indian J Pathol Microbiol. 2010;53:455-9.

7. Fairly NH, Mackie FP. The clinical and biochemical syndrome in lymphadenoma and allied diseases involving the mesenteric lymph glands. Br Med J. 1937;1:375-80.

8. Holmes GK, Prior P, Lane MR, Pope D, Allan RN. Malignancy in coeliac disease-effect of a gluten free diet. Gut. 1989;30:333-8.

9. Verbeek WH, Van De Water JM, Al-Toma A, Oudejans JJ, Mulder CJ, Coupe VM. Incidence of enteropathy-associated T-cell lymphoma: a nation-wide study of a population-based registry in The Netherlands. Scand J Gastroenterol. 2008;43:1322-8.

10. Gale J, Simmonds PD, Mead GM, Sweetenham JW, Wright DH. Enteropathy-type intestinal T-cell lymphoma: clinical features and treatment of 31 patients in a single center. J Clin Oncol. 2000;18:795-803.

\section{Biliary atresia with cytomegalovirus infection and its response to ganciclovir}

\section{Introduction}

Biliary atresia (BA) is a condition in which the normal extra hepatic biliary system is disrupted. Biliary atresia affects approximately 1 in 10,000 - 15,000 births and occurs in 2 distinct clinical forms: fetal-embryonic (or syndromic) and perinatal (or acquired). The fetal embryonic form is characterized by early cholestasis, appears in the first 2 weeks of life, and accounts for $10-35 \%$ of all cases. In this form, the bile ducts are discontinuous at birth and 10-20\% of affected neonates have associated congenital defects including situs inversus, polysplenia, malrotation, intestinal atresia and cardiac anomalies, among others. The perinatal form of biliary atresia accounts for the remaining 65-90\% cases. This form is typically found in neonates and infants aged 2-8 weeks. Progressive inflammation and obliteration of the extra hepatic bile ducts occurs after birth. This form is not associated with congenital anomalies. Infection with cytomegalovirus (CMV), group C rotavirus and reovirus type 3 have been implicated in these patients. ${ }^{1}$ Immune mediated ductal injury are important in the 